\title{
A novel approach for recycling of kerf loss silicon from cutting slurry waste for solar cell applications
}

\author{
T.Y. Wang ${ }^{\text {a }}$ Y.C. Lin ${ }^{\text {a }, ~ C . Y . ~ T a i ~}{ }^{\text {a }}$, R. Sivakumar ${ }^{\text {, }}$ D.K. Rai ${ }^{\text {a,b }}$, C.W. Lan ${ }^{\text {a,c,* }}$ \\ a Department of Chemical Engineering, National Taiwan University, Roosevelt Road, Taipei, Taiwan 10617, ROC \\ ${ }^{\mathrm{b}}$ Department of Physics and Materials Science and Engineering, Jaypee Institute of Information Technology University, Noida 201307, India \\ ${ }^{\mathrm{c}}$ Photovoltaics Technology Center, Industrial Technology Research Institute, Hsin-chu, Taiwan, ROC
}

\section{A R T I C L E I N F O}

\section{Article history:}

Received 19 December 2007

Received in revised form

25 March 2008

Accepted 12 April 2008

Communicated by M. Tischler

Available online 2 May 2008

PACS:

81.30.- $\mathrm{t}$

61.72.-y

84.60.Jt

\section{Keywords:}

A1. Directional solidification

A1. Impurities

A1. Purification

B2. Semiconducting materials

B2. Semiconducting silicon

B3. Solar cells

\begin{abstract}
A B S T R A C T
A great challenge in recycling of silicon cutting kerf loss is the complete removal of silicon carbide particles. High-gravity centrifugation using a heavy medium with a specific gravity in between that of silicon carbide and silicon is not effective for the submicron particles. In this paper, a novel recycling process for obtaining silicon from the kerf loss powders is reported. The obtained silicon after directional solidification was found to be of solar grade. The average lifetime and resistivity of grown crystal were measured to be $1.02 \mu \mathrm{s}$ and $0.7 \Omega \mathrm{cm}$, respectively, which were close to the original sawing silicon and casted pure Si ingots. The energy conversion efficiencies of the solar cells fabricated from the recycled and pure silicon were found comparable.
\end{abstract}

(c) 2008 Elsevier B.V. All rights reserved.

\section{Introduction}

The photovoltaic (PV) industry is going through a rapid growth. In 2006 alone, the global PV production was over $2 \mathrm{GW}$. The majority of PV cells are made of silicon, which is mainly produced from the energy-intensive Siemens process [1]. As per current status, the wafer shares more than $65 \%$ of the cost for solar cells, but on the other hand, more than $40 \%$ of the high-purity silicon is wasted during wafer slicing. The kerf silicon loss is in the form of slurry mixed with the cutting fluid and abrasive silicon carbide ( $\mathrm{SiC})$ particles, as well as the worn down metals from the saw wire. Although the kerf loss silicon particles remain in high purity, recycling them from the slurry waste for their reuse has not yet been successful [2]. The major challenges in recycling are the complete removal of SiC particles, which are generally higher in

\footnotetext{
* Corresponding author at: Department of Chemical Engineering, National Taiwan University, No. 1, Sec. 4, Roosevelt Road, Taipei, Taiwan 10617, ROC. Tel./ fax: +886223633917.

E-mail address: cwlan@ntu.edu.tw (C.W. Lan).
}

content than silicon, as well as the metals, whose content is up to tens of thousands of ppm. Since, sizes of the particles are of micron or submicron order, the high-gravity centrifugation is not effective for their removal. Particularly, SiC is highly chemically inert and difficult to be washed away by acid solutions.

In the present work, the silicon slurry waste was obtained from the Chu-Nan's factory of the Sino-American silicon (SAS) products Inc., Taiwan. The slurry, which was produced from cutting of single-crystalline silicon ingot with resistivity in the range of $0.5-5 \Omega \mathrm{cm}$, was pre-treated using a centrifuge in order to separate considerably larger $\mathrm{SiC}$ particles before arrival into our laboratory. This may be mentioned that before pre-treatment, SiC/Si volume ratio in the waste was $\sim 3$ which reduced to $\sim 1$ after the pretreatment. The as-received slurry consists of $35 \mathrm{wt} \% \mathrm{SiC}, 31 \mathrm{wt} \%$ lubricating oil (ethylene glycol), $6 \mathrm{wt} \%$ metals from cutting wire, $1 \mathrm{wt} \%$ glass from the ingot mounting stage, and $27 \mathrm{wt} \%$ kerf silicon fine particles of the order of micron size.

Here, we report a novel process for almost complete removal of impurity contents particularly $\mathrm{SiC}$, hitherto impossible to remove, from the silicon slurry. We have compared the properties of recycled silicon with that of the pure silicon. Our findings show 
that the recycled silicon bears properties of solar grade silicon. This, in turn, establishes the developed process apt for recycling of silicon slurry from kerf loss for PV applications on commercial level.

\section{Experimental procedure}

The recycling of the as-obtained slurry was carried out using chemical/physical processing steps like chemical treatment, highgravity centrifugation, high-temperature precipitation technique and directional solidification which are described in detail in the results and discussion part. The slurry was divided into four batches weighing about 550-600 g for the recycling and growth of silicon ingot.

Before recycling of the slurry, particle size measurement was carried out using static light scattering (Beckman, Coulter LS230). The content of $\mathrm{SiC}(<10.7 \mathrm{wt} \%)$ was measured in the powder of the raw material after high-gravity centrifugation using Horiba carbon/sulfur analyzer (Leco, model CS-244). We also carried out density measurement using automatic gas displacement pycnometer (AGDP) (Micromeritics, AccuPyc 1330) for reconfirmation and measurement of higher SiC content. The level of metal impurities in the slurry was measured before recycling process, during recycling process, and also after the crystal growth by a high-resolution glow discharge mass spectrometry (GDMS, Model VG9000). For the measurement, $2 \mathrm{~g}$ powder of the material before recycling and during recycling and blocks of size $5 \mathrm{~mm} \times 10 \mathrm{~mm} \times 20 \mathrm{~mm}$, cut from the ingot, from each batch were sent to Shiva technologies, USA for the measurement. For quantitative evaluation of substitutional carbon in the grown ingot, FTIR (Nicolet Magna 550) was used. The carbon content was evaluated at $605 \mathrm{~cm}^{-1}$ corresponding to absorption peak of substitutional carbon in the silicon lattice. For the measurement, vertically sliced crystal wafers of thickness $12 \mathrm{~mm}$ from each of the four ingots were used. The same wafers were used for the minority carrier lifetime mapping and resistivity measurement using wafer tester system (Semilab, model WT2000) and sheet resistance measuring system (Keithley, Model RT-70/RG-5), respectively. The measurement was carried out on the whole wafer surface.

For fabrication of solar cells, wafers were cut from the center of the grown ingot of the recycled silicon and pure casted silicon. Solar cells with a simple $\mathrm{p}-\mathrm{n}$ junction without gettering and texturing were fabricated using wafers of size about $15 \mathrm{~mm} \times 15 \mathrm{~mm} \times 350 \mu \mathrm{m}$. A phosphorus-doped glass (Honeywell, USA) film was spin coated on the wafer and the $\mathrm{n}^{+}$emitter layer was formed by rapid thermal diffusion at $850{ }^{\circ} \mathrm{C}$ for $1 \mathrm{~min}$. The substrates were further etched by a buffered HF solution to remove the glass film from the surface. An antireflection coating of indium-tin oxide of thickness $(\sim 70 \mathrm{~nm})$ was formed by sputtering on the wafer surfaces. Finally, the back surface field contact was formed by printing aluminum paste on the back surface and firing at $880^{\circ} \mathrm{C}$. The front metallization was found unnecessary for such small cells.

\section{Results and discussion}

Fig. 1 shows a typical particle size distribution of impurities in the slurry waste (inset). The major peak around $10 \mu \mathrm{m}$ particle size is contributed by $\mathrm{SiC}$ particles, while the smaller peak is mainly due to $\mathrm{Si}$, but $\mathrm{SiC}$ debris and metal powders also share this peak.

For recycling, the as-obtained slurry was first cleaned by using acetone to remove oil, and finally with nitric acid to dissolve the

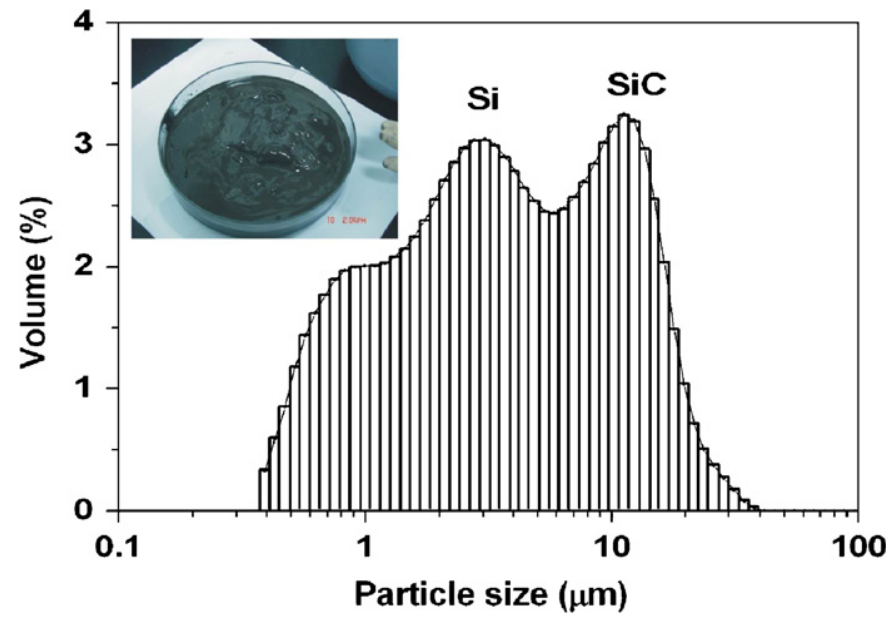

Fig. 1. Particle size distribution of $\mathrm{Si}$ and $\mathrm{SiC}$ in the as-received slurry. Photograph of as-received slurry shown in the inset.

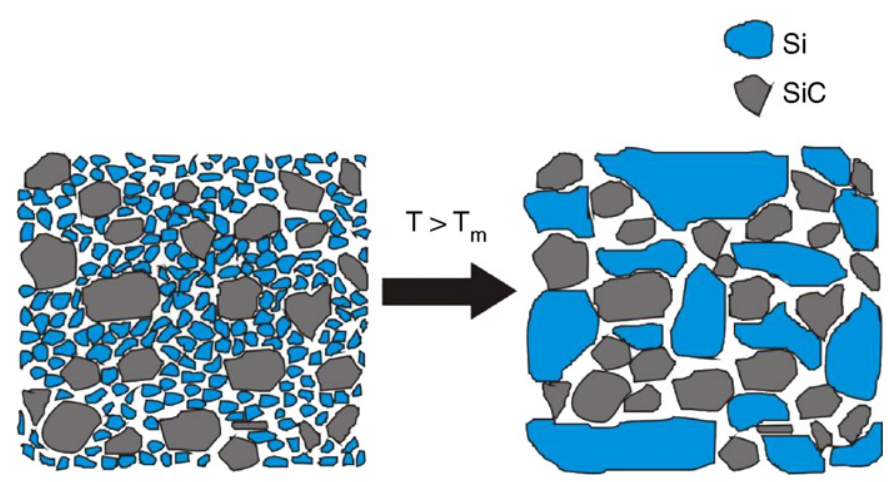

Fig. 2. Schematic illustration of silicon conglomeration during high-temperature treatment.

metal particles followed by centrifugation at $3300 \mathrm{rpm}(2100 \mathrm{G})$ for $60 \mathrm{~min}$ to remove the cleaning liquid. In order to reduce the content of $\mathrm{SiC}$ particles, a high-gravity centrifugation was carried out using a centrifuge. A heavy fluid with specific gravity between that of $\mathrm{Si} \mathrm{(2.33)} \mathrm{and} \mathrm{SiC}$ (3.2) was added into the above-cleaned slurry and centrifuged at $3300 \mathrm{rpm}(2100 \mathrm{G})$ for $60 \mathrm{~min}$. During centrifugation, $\mathrm{SiC}$ settles down to the bottom and Si floats on the liquid surface. The floating material, consisting of mainly $\mathrm{Si}$, was taken out and cleaned with acetone and deionized (DI) water to get the raw material. The results obtained from Horiba carbon/ sulfur analyzer and density measurement show that SiC concentration after high-gravity centrifugation in the raw material is still 7-15 wt\%. In order to reduce the $\mathrm{SiC}$ content further, repeated high-gravity centrifugation was performed and concentration measurement was done using the above techniques. However, even after three times of centrifugation, SiC content remained almost same, i.e. about $10 \mathrm{wt} \%$ in the raw material. It is concluded that it is impossible to remove SiC particles completely from the slurry by centrifugation process only. It may be due to very small particle size of $\mathrm{SiC}$ remaining in the raw material. Therefore, in order to remove $\mathrm{SiC}$ content further, we have developed a new method of high temperature (HT) treatment.

For HT treatment, the Si/SiC powder was first palletized. The pellet was placed in a silicon nitride coated quartz crucible of inner diameter $46 \mathrm{~mm}$ and was subjected to the HT treatment at about $1470{ }^{\circ} \mathrm{C}$ for several hours in argon atmosphere using an induction furnace. Due to difference in the melting points of the constituents, Si started oozing out of the material in the form of 
clusters during HT treatment. The formation of clusters is schematically shown in Fig. 2. Once the cluster formation was over, the material was cooled down. The silicon clusters and SiC could now be easily separated by simple water cleaning because $\mathrm{Si}$ clusters were non-adherent to the SiC particles. Fig. 3 shows the collected clean Si conglomerate after the HT treatment and water cleaning. Further, most of the other impurities were segregated towards the surface of the Si conglomerates during the cooling down stage. These impurities were washed away from the conglomerate skin using hydrofluoric acid. The silicon was further cleaned by DI water and used for crystal growth by directional solidification using a silicon nitride-coated quartz crucible.

During crystal growth, the crucible lowering speed was kept as $10 \mathrm{~mm} / \mathrm{h}$ and temperature gradient was about $20^{\circ} \mathrm{C} / \mathrm{cm}$. Ingot of $46 \mathrm{~mm}$ diameter and $30 \mathrm{~mm}$ height was grown from the recycled silicon using directional solidification. This is to mention that the directional solidification is also known to remove the impurities, including $\mathrm{SiC}$, having low segregation coefficients and different melting points $[3,4]$. To verify the result, the wafers of grown ingot were inspected by SEM and no SiC particles were observed in the microstructure. This shows that the almost complete removal of $\mathrm{SiC}$ is achieved by the proposed process.

Further, the initial amount of slurry taken was $\sim 500-600 \mathrm{~g}$, as mentioned above, consisting $135-162$ g of silicon. After casting, silicon ingots weighing $\sim 60-70 \mathrm{~g}$ were obtained. Thus, the overall yield of the recycled silicon was found to be $\sim 45 \%$.

Table 1 shows a typical GDMS result of the average values of the impurity in slurry at different stages of recycling. The results clearly show that most of the metal impurities except, iron, aluminum, calcium, magnesium and copper, were almost removed after the cleaning. The acid treatment was found to be effective in reducing the metallic impurities by a factor of around two or for some metals even more. Residual impurities were further reduced by HT treatment as shown in the table. But some impurities like iron, copper, chromium and aluminum were still present in the material well beyond their acceptable limits. Since the segregation coefficients of the iron, copper, chromium and aluminum are very small, i.e. $6.4 \times 10^{-6}, 8 \times 10^{-4}, 1.1 \times 10^{-5}$ and $2.8 \times 10^{-3}$, respectively, these impurities could well be reduced to the acceptable limit after directional solidification. Other small impurities like $\mathrm{Ni}, \mathrm{Zn}, \mathrm{Pd}, \mathrm{Co}$, Ti Ca, Mg were also removed to their values, well below the acceptable limit, for solar cell applications as shown in the table. But, the content of phosphorous was reduced to 1.1-1.7 ppmw only in the grown crystal by directional

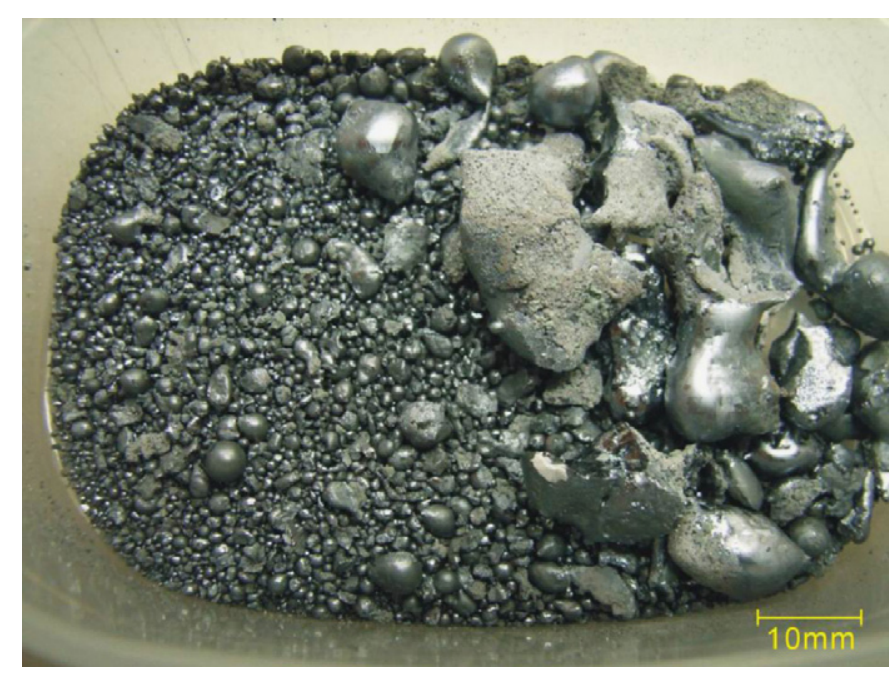

Fig. 3. Photograph of cleaned silicon conglomerates after high-temperature treatment.
Table 1

Level of metal impurities measured by high-resolution glow discharge mass spectrometry (GDMS)

\begin{tabular}{lllll}
\hline Element & Concentration $(\mathrm{ppm}$ w) & & \\
\cline { 2 - 4 } & $\begin{array}{l}\text { Original } \\
\text { slurry }\end{array}$ & $\begin{array}{l}\text { After acid } \\
\text { treatment }\end{array}$ & $\begin{array}{l}\text { After HT } \\
\text { treatment }\end{array}$ & $\begin{array}{l}\text { After } \\
\text { directional } \\
\text { solidification }\end{array}$ \\
& & 370 & 75 & $<0.05$ \\
\hline $\mathrm{Fe}$ & 3000 & 9 & 6.5 & 0.07 \\
$\mathrm{Ni}$ & 12 & 65 & 35 & 2.4 \\
$\mathrm{Cu}$ & 450 & 1.1 & 0.2 & $<0.05$ \\
$\mathrm{Zn}$ & 180 & 0.22 & $<0.05$ & $<0.05$ \\
$\mathrm{~Pb}$ & 0.1 & 30 & 12 & $<0.1$ \\
$\mathrm{Cr}$ & 11 & 100 & 35 & $<0.05$ \\
$\mathrm{Al}$ & 37 & 0.29 & 0.05 & $<0.01$ \\
$\mathrm{Co}$ & 0.73 & 13 & 8 & $<0.01$ \\
$\mathrm{Ti}$ & 16 & 430 & 3.5 & $<0.5$ \\
$\mathrm{Ca}$ & 290 & 360 & 1.6 & $<0.05$ \\
$\mathrm{Mg}$ & 130 & 1.5 & 0.65 & 0.49 \\
$\mathrm{~B}$ & 0.3 & 4.3 & 5.9 & 1.7 \\
$\mathrm{P}$ & 7.3 & & & \\
\hline
\end{tabular}

solidification. It is known that the complete removal of boron and phosphorous from the slurry is not possible either by chemical cleaning or by HT treatment, but they can be reduced only slightly through directional solidification because of their high segregation coefficient $(0.35$ and 0.8 , respectively, for phosphorous and boron) [5-7]. The source of phosphorous content in the slurry was identified to be the glass mounting stage during wafer slicing, which contained about $2.4 \mathrm{wt} \%$ of phosphorous inside. Apparently, in the acid washing stages, the glass was not completely removed. It is believed that this problem can be avoided by replacing the mounting stage by graphite. Because of the existence of phosphorous, the grown ingot turned into $n$-type near the top portion of the crystal during growth because of the fact that the segregation coefficient of phosphorous is smaller than boron. Further, the table shows the average copper content to be 2.4 ppmw. The copper is well-known for killing carrier lifetime, as well as it quickly diffuses into the bulk. However, it is known that in directional solidification, impurity content varies along the length of the crystal being small at the beginning and more towards the end of the crystal growth. Therefore, copper content is expected to be within the acceptable limit for solar cell applications in the middle or lower part of the crystal.

The FTIR results show that the content of the substitutional carbon in the wafer of grown $\mathrm{Si}$ ingot is $4.86 \mathrm{ppma}$, which is well within the range (0.5-5 ppma) of acceptable limit for solar cell applications.

The resistivity was found to increase from $0.5 \Omega \mathrm{cm}$ at the bottom to $1.4 \Omega \mathrm{cm}$ at the center and then decreased again to $0.5 \Omega \mathrm{cm}$ at the top of ingot. The minority carrier lifetime was also found varying from 0.45 to $1.5 \mu$ s and decay again to $0.7 \mu$ s along the crystal growth. This may be attributed to the charge compensation as a result of the coexistence of phosphorous and boron. The average minority carrier lifetime and resistivity for the grown ingot of recycled silicon were found to be $1.02 \mu \mathrm{s}$ and $0.7 \Omega \mathrm{cm}$, respectively, while those of casted pure silicon were found to be $3.6 \mu \mathrm{s}$ and $4.1 \Omega \mathrm{cm}$. The lower resistivity and lifetime of recycled silicon ingot in comparison to the casted pure silicon may be due to phosphorous residues in the crystal.

Solar cells were made taking at least five wafers of size about $15 \mathrm{~mm} \times 15 \mathrm{~mm} \times 350 \mu \mathrm{m}$ from each of the four grown Si ingots. Because of the impurities segregation, the solar cell energy transfer efficiency was found to vary according to the wafer position in the crystals being the lowest impurity in the wafer from the bottom of the ingot. The best energy conversion 
efficiency $(\eta)$ of the solar cells made from the recycled silicon was found to be $11.6 \%\left(V_{\mathrm{oc}}=503 \mathrm{mV}\right.$ and $\left.J_{\mathrm{sc}}=37.2 \mathrm{~mA} / \mathrm{cm}^{2}\right)$, which was comparable to that of casted pure $\mathrm{Si}$ ingot $(\eta=11.3 \%$, $V_{\mathrm{oc}}=513 \mathrm{mV}, J_{\mathrm{sc}}=28.9 \mathrm{~mA} / \mathrm{cm}^{2}$ ). It may be mentioned that the solar cell fabrication process was not optimized therefore; efficiency of the fabricated cell was not so high. Further, the surface texturing and passivation were also not considered during the cell fabrication. Above results show that recycled silicon possesses properties of solar grade silicon and may be used for solar cell applications.

\section{Conclusion}

To summarize our results, the kerf loss silicon was successfully recycled by a novel process discussed above to obtain solar grade silicon. The overall yield of the recycled silicon was $\sim 45 \%$. Most of metal impurities in the slurry waste were removed by the recycling process. Most importantly, $\mathrm{SiC}$ particles were almost completely removed from the slurry by HT treatment which is reported for the first time herein. The average minority carrier lifetime and resistivity of the grown crystal were found to be slightly lower than those of original sawing $\mathrm{Si}$ and casted pure $\mathrm{Si}$ ingots. The efficiency of fabricated solar cell was found to be comparable with the one from the pure Si crystals. The recycling and characterization results show that the proposed process is apt for recycling of kerf loss silicon. Further to add, the discussed process can be scaled up for the commercial production, but with certain limitations. During chemical/physical treatment, prolonged use of acid may have corrosive effect on the centrifuge surface. Therefore, use of Teflon made disk centrifuge may be used on commercial level.

\section{Acknowledgments}

This work was supported by Phoenix Silicon International Corporation, Taiwan, Research Grant NSC 95-ET-7-002-003-ET from the Bureau of Energy of Taiwan, and the top-research project from National Taiwan University. The generous material support from the Chu-Nan factory of SAS is also highly acknowledged.

\section{References}

[1] A. Luque, S. Hegedus, Handbook of Photovoltaic Science and Engineering, Wiley Ltd., New York, 2003 (Chapter 5).

[2] D. Sarti, R. Einhaus, Sol. Energy Mater. Sol. Cells 72 (2002) 27.

[3] A. Muhlbauer, V. Diers, A. Walther, J.G. Grabmaier, J. Crystal Growth 108 (1991) 41.

[4] A. Muller, P.M. Nasch, Proc. Photovoltaic Programme (2004).

[5] K. Morita, T. Miki, Intermetallics 11 (2003) 1111.

[6] B.G. Gribov, K.V. Zinov'ev, Inorg. Mater. 39 (2003) 653.

[7] C.P. Khattak, D.B. Joyce, F. Schmid, Sol. Energy Mater. Sol. Cells 74 (2002) 77. 